\title{
Generalized Ligamentous Laxity; a Parameter Should not to be Forgotten in Preoperative Planning of Adolescent Idiopathic Scoliosis
}

\author{
Ebrahim Ghayem Hasankhani ${ }^{1}$, Farzad Omidi-Kashani ${ }^{1^{*}}$ \\ ${ }^{1}$ Orthopedic Research Center, Emam Reza Hospital, Faculty of Medicine, Mashhad University of Medical Sciences, Mashhad, Iran \\ * Corresponding author: Farzad Omidi-Kashani, No 226, South Bozorgmehr 20, Sajad Street, Mashhad, Iran. Tel.: +98-9155149248, Fax: +98-5118595023, E-mail: \\ omidif@mums.ac.ir
}

\section{A B S T R A C T}

Background: Many factors effect on management (surgical and nonsurgical) of adolescent idiopathic scoliosis (AIS).

Objectives: The purpose of this study was evaluation of the effects of generalized ligamentous laxity (GLL) on surgical treatment of AIS.

Materials and Methods: 72 patients with AIS were studied between 2002 and 2009. 24 cases (33.4\%) were placed in group A (normal) while 48 patients (66.6\%) with GLL in group B. Our threshold for adding anterior approach was a curve which could not be corrected to $<50^{\circ}$ on the supine lateral bending view.

Results: The mean age and follow up period were 16.4 (12-22 years) and 3.8 (2-6.5 years), respectively. In the first group, 12 (50\%) were operated with combined anterior and posterior approaches while in the later; there were only $6(12.5 \%)$. Curve correction was $73.3 \%$ in patients with GLI and $57.1 \%$ in patients without it. Both of these differences were significant statistically $(\mathrm{P}=0.001)$.

Conclusions: In preoperative planning of surgical treatment of AIS, GLL is an important factor. In this special group of patients due to much more flexibility, relatively larger scoliotic curves can be safely treated by single posterior approach.

Keywords: Idiopathic; Scoliosis; Ligaments; Surgical Procedures, Operative

\section{Background}

AIS is one of the most common spinal deformities with no definite etiology, although there are some probable causes reported to be important in creating and exaggerating it $(1,2)$. The deformity can be treated with observation alone, bracing or surgery. In surgical treatment, the base of the remedy is on the spinal arthrodesis. In acquiring a successful treatment, it should be tried to fuse as little motion segment as possible and also to operate as few and less aggressive approaches as possible (3).

One of the indices that thought to be important in preoperative planning of this disorder is scoliotic curve flexibility and one of the factors that is critical in curve flexibility besides Cobb angle, curve location, sex and age; it seems to be GLL (4-6). According to our knowledge, the effect of GLL on the surgical treatment of AIS has not been directly investigated yet.

\section{Objectives}

In this study we tried to analyze the effects of GLL in the surgical treatment of AIS.

\section{Materials and Methods}

In this prospective cohort study, we studied 83 surgically treated cases with AIS between May 2002 and January 2009. Preoperatively, in all the patients standing radiographs and supine lateral bending views and in selected cases, total spine MRI and pulmonary function tests were acquired. All the patients assigned the informed consent.

Flexibility and correction percentages were acquired as below:

Flexibility percentage $(\%)=\left(\right.$ upright $\mathrm{Cobb}^{\circ}$ - supine bending $\left.\mathrm{Cobb}^{\circ}\right) /$ upright $\mathrm{Cobb}^{\circ} \times 100$

Correction percentage $(\%)=\left(\right.$ upright $\mathrm{Cobb}^{\circ}{ }_{\text {postop }}$ - up-

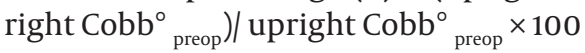

-Article type: Research Article; Received: 04 Oct 2011, Revised: 22 Feb 2012, Accepted: 10 Mar 2012; DOI: 10.5812/ircmj.2554

Implication for health policy/practice/research/medical education:

This study focused on the effects of generalized ligamentous laxity in the surgical treatment of adolescent idiopathic scoliosis.

Please cite this paper as:

Ghayem-Hasankhani E, Omidi-Kashani F. Generalized Ligamentous Laxity; a Parameter Should not to be Forgotten in Preoperative Planning of Adolescent Idiopathic Scoliosis. Iran Red Cres Med J.2012;14(11):702-4. DOI: 10.5812/ircmj.2554

Copyright (C) 2012, Iranian Red Crescent Medical Journal; Published by Kowsar Corp.

This is an Open Access article distributed under the terms of the Creative Commons Attribution License (http://creativecommons.org/licenses/by/3.0), which permits unrestricted use, distribution, and reproduction in any medium, provided the original work is properly cited. 
All participants were examined for GLL using the adapted Beighton-Horan scale (7). This laxity assessment, was first devised by Carter and Wilkinson in 1964 and later modified by Beighton et al in 1973 (8), measures the following five elements:

1-Passive opposition of the thumb to the flexor aspect of the forearm (1 point per hand)

2-Passive hyperextension of the 5th metacarpophalangeal joint $>90^{\circ}$ (1point per hand)

3-Hyperextension of the elbows $>15^{\circ}$ (1 point per arm)

4-Hyperextension of the knees (1 point per leg)

5-Forward flexion of the trunk with knees extended and palms flat on floor (1 point)

All elements are added together to give an overall ligamentous laxity score ranging from 0 (tight) to 9 (hyperlax). After the assessment, we arbitrary stratified the participants into one of two groups: group A (tight group; scores 0-4) and group B (loose group; scores 5-9).

Our threshold for adding anterior approach was a curve which can't be corrected to $<50^{\circ}$ on the supine bending lateral view. We routinely instrumented the spine with combined hooks and pedicular screws for segmental fixation. The patients with less than 2 years following up were excluded from the study.

Statistical analysis was performed by the Mann-Whitney test for comparing scoliotic curves with the SPSS statistical software (Version 15, Chicago, IL, USA). P $<0.05$ was considered statistically significant.

\section{Results}

Initially, we had 83 patients fulfilled the criteria of the study, but later 8 patients cannot be accessed and followed up and therefore they were exited from it. Another 3 cases were also excluded due to the underlying syrinx. Finally, we considered 72 cases (18 male; 25\%, and 54 female; $75 \%)$. The mean age and follow up period were 16.4 (12-22 years) and 3.8 (2-6.5 years), respectively.

24 cases (33.4\%) were placed in group A while 48 patients (66.6\%) in group B. In the first group, 12 (50\%) were operated with combined approaches while in the later; there were only 6 (12.5\%). Correction percentage in both groups was depicted in table 1. Postoperative complications were not remarkable.

Table 1. Correction percentage of the scoliosis in our patients

\begin{tabular}{|c|c|c|c|c|c|c|}
\hline Groups & $\begin{array}{l}\text { Preop- } \\
\text { erative } \\
\text { Curve, } \\
\text { Mean } \pm \\
\text { SD }\end{array}$ & & $\begin{array}{l}\text { Flexibil- } \\
\text { ity Per- } \\
\text { centage, } \\
\text { Mean } \pm \\
\text { SD }\end{array}$ & $\begin{array}{l}\text { Postop- } \\
\text { erative } \\
\text { Curve, } \\
\text { Mean } \pm \\
\text { SD }\end{array}$ & & $\begin{array}{l}\text { Correc- } \\
\text { tion } \\
\text { Percent- } \\
\text { age }\end{array}$ \\
\hline A & $\begin{array}{l}71.17 \\
14.98\end{array}$ & \pm & $31.2 \pm 13.3$ & $\begin{array}{l}30.52 \\
9.15\end{array}$ & \pm & $58.1 \%$ \\
\hline B & $\begin{array}{l}66.73 \\
12.33\end{array}$ & \pm & $41.4 \pm 16.5$ & $\begin{array}{l}17.84 \\
4.48\end{array}$ & \pm & $73.3 \%$ \\
\hline P value & 0.52 & & 0.01 & 0.013 & & 0.001 \\
\hline
\end{tabular}

\section{Discussion}

The main goal of surgery in AIS is prohibition of the curve aggravation. The secondary gains are correction of the curve as safe as possible, balancing the trunk decompensation (if present), rib hump elimination and shoulders leveling; while fusing as few vertebrae as possible. In acquiring these goals, numerous factors including surgical technique, type of the instrumentation and deformity, maturity, sex, Cobb angle, location and flexibility of the curve should be taken into account (5,9-11).

The prevalence of GLL in our study was $66.6 \%$ and was surprisingly high relative to some other studies like the one conducted by Stewart and Burden (12). They found a prevalence of $24 \%$ with a criteria $>4 / 9$ for GLL. In this study we cannot justify it but geographic differences among the patients or other unknown parameters may play some role. Therefore in preoperative planning of every patient who is candidate for AIS surgery, GLL as a good prognostic index should be checked carefully. In this special group of patients due to much more flexibility, relatively larger scoliotic curves can be safely treated by single posterior approach.

\section{Acknowledgements}

None declared.

\section{Financial Disclosure}

None declared.

\section{Funding/Support}

None declared.

\section{References}

1. Girardo M, Bettini N, Dema E, Cervellati S. The role of melatonin in the pathogenesis of adolescent idiopathic scoliosis (AIS). Eur Spine J. 2011;20(Suppl 1):S68-74.

2. Wang WJ, Yeung HY, Chu WC, Tang NL, Lee KM, Qiu Y, et al. Top theories for the etiopathogenesis of adolescent idiopathic scoliosis. J Pediatr Orthop. 2011;31(1 Suppl):S14-27.

3. Rose PS, Lenke LG. Classification of operative adolescent idiopathic scoliosis: treatment guidelines. Orthop Clin North Am. 2007;38(4):521-9, vi.

4. Marks M, Petcharaporn M, Betz RR, Clements D, Lenke L, Newton PO. Outcomes of surgical treatment in male versus female adolescent idiopathic scoliosis patients. Spine (Phila Pa 1976). 2007;32(5):544-9.

5. Chen ZQ, Zhao YF, Bai YS, Liu KP, He SS, Wang CF, et al. Factors affecting curve flexibility in skeletally immature and mature idiopathic scoliosis. J Orthop Sci. 2011;16(2):133-8.

6. Ameri E, Behtash H, Mobini B, Omidi-Kashani F, Momeni B. Radiographic outcome of surgical treatment of adolescent idiopathic scoliosis in males versus females. Scoliosis. 2008;3:12.

7. Read MTF. A practical guide to sports injuries. Boston: ButterworthHeinemann; 2000.

8. Krivickas LS, Feinberg JH. Lower extremity injuries in college athletes: relation between ligamentous laxity and lower extremity muscle tightness. Arch Phys Med Rehabil.1996;77(11):1139-43.

9. Clamp JA, Andrews JR, Grevitt MP. A study of the radiologic predictors of curve flexibility in adolescent idiopathic scoliosis. $J$ Spinal Disord Tech. 2008;21(3):213-5. 
10. Deviren V, Berven S, Kleinstueck F, Antinnes J, Smith JA, Hu SS. Predictors of flexibility and pain patterns in thoracolum bar and lumbar idiopathic scoliosis. Spine (Phila Pa 1976). 2002;27(21):2346-9.

11. Vora V, Crawford A, Babekhir N, Boachie-Adjei O, Lenke L, Peskin $\mathrm{M}$, et al. A pedicle screw construct gives an enhanced posterior correction of adolescent idiopathic scoliosis when compared with other constructs: myth or reality. Spine (Phila Pa 1976). 2007;32(17):1869-74.

12. Stewart DR, Burden SB. Does generalised ligamentous laxity increase seasonal incidence of injuries in male first division club rugby players? BrJ Sports Med. 2004;38(4):457-60. 